\title{
Anomalous Origin of Obturator Artery from the Internal Iliac Artery
}

\author{
Origen Anómalo de la Arteria Obturatriz de la Arteria Iliaca Interna
}

\author{
"Dinesh Kumar \& **Gayatri Rath
}

KUMAR, D. \& RATH, G. Anomalous origin of oburator artery from the internal iliac artery. Int. J. Morphol., 25(3):639-641, 2007.

SUMMARY: Obturator arteryis frequently a branch of anterior division of internal iliac artery or one of the parietal branches of internal iliac artery. But it has attracted attention of pelvic surgeons and anatomists and radiologists because of the high frequency of the variation in its course and origin. The present report demonstrates obturator artery to be arising from the posterior division of internal iliac artery out of 316 pelvises, a rare observation in Indian population. The variation is correlated developmentally and its clinical implications are also discussed.

KEYWORDS: Obturator artery; Anatomical variation.

\section{INTRODUCTION}

Vascular variations have always been a subject of controversy, as well as curiosity, because of their clinical significance. There is, perhaps, no artery of proportionate size having as variable an origin as that of the obturator artery (OBA), nor has any similar artery attracted greater attention among pelvic surgeons, anatomists and radiologists (Pick et al., 1942). Anson's group has reported the occurrence of a variation of OBA in about $48 \%$ of individuals. Regarding the variability in the origin of OBA, it is documented that in $41.4 \%$ of cases it may arise from the common iliac or anterior division of internal iliac, in $25 \%$ from inferior epigastric, in $10 \%$ from superior gluteal, in $10 \%$ from interior gluteal/internal pudendal trunk, in $4.7 \%$ from inferior gluteal, in 3.8\% from internal pudendal and in $1.1 \%$ from external iliac artery (Bergman et al., 1988).

The present case is an observation of unilateral variation in the origin of left OBA. The variant artery was arising from the posterior division of internal iliac artery, a rare observation in Indian population. Therefore an attempt has been made to highlight its clinical implications in relation to the anomalous origin from the internal iliac artery.

\section{MATERIAL AND METHOD}

Out of 316 pelvises of formalin fixed adult cadavers studied it was observed that in one adult male cadaver in the department of Anatomy of Vardhman Mahavir Medical College and Safdarjung hospital, New Delhi, the left obturator artery was arising from the posterior division of internal iliac artery. The right side artery showed no variation of any sort, in its origin and course.

The course and branches of the variant OBA was observed till its exit from the obturator foramen and photographs were taken and labeled.

\section{RESULTS}

The left OBA was found to be arising from the posterior division of internal iliac artery lying just medial to anterior division of internal iliac artery (Fig.1). It then traveled forwards, infero-lateral to the common trunk of internal pudendal and inferior gluteal artery, it further coursed forwards and downwards lying over the ischio-coccygeal part of levator ani to reach the upper part of obturator foramen, running parallel and inferior to the obturator nerve.

\footnotetext{
* Department of Anatomy, Maulana Azad Medical College, New Delhi, India.

** Department of Anatomy, Vardhman Mahavir Medical College, New Delhi, India.
} 
Medially it was related to the left ureter and ductus deferens. Throughout its course except near its origin it was related to the obturator fascia and obturator internus muscle laterally. Leaving the obturator canal, it divided into anterior \& posterior branches. The rest of its branches didn't show any variation.

The total length of the left OBA was observed to be $71 \mathrm{~mm}$. It was given off at a distance of $8 \mathrm{~mm}$, from the point of bifurcation (into anterior and posterior division) of the left internal iliac artery. It gave one muscular branch at a distance of $44 \mathrm{~mm}$, from its origin and a small branch tothe head of the femur.

The right OBA was noted to be arising from the anterior division of the internal iliac artery and traveled along obturator nerve to reach the obturator foramen. Its length was measured to be $54 \mathrm{~cm}$.

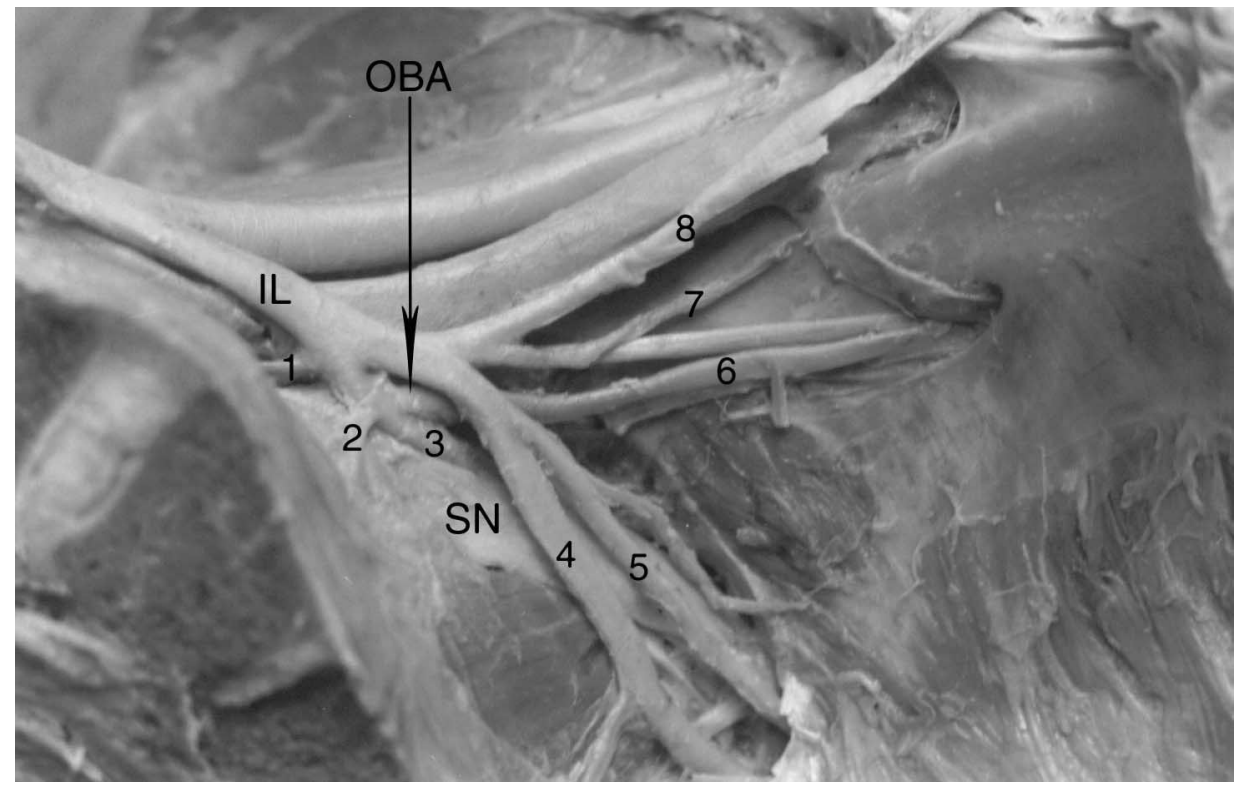

Fig. 1. Photograph showing all the branches of left internal iliac artery (IL). 1. Iliolumbar artery; 2. Lateral sacral artery; 3. Superior gluteal artery; 4. Inferior gluteal artery; 5. Internal pudendal artery; 6 . Obturator artery; 7. Inferior vesical artery; 8. Superior vesical artery. The arrow depicts the origin of left OBA from posterior division of internal iliac artery. SN. Sciatic nerve; OBN obturator nerve.

\section{DISCUSSION}

The obturator artery has been documented to be arising from all possible neighbouring arteries, i.e. common iliac, external iliac, from any branch of internal iliac in either sex. (Arey, 1963). In the vast majority of cases, the OBA originates within the pelvis from external iliac or the hypogastric (internal iliac artery), the anterior or posterior division of the latter, or a branch of either division (Parson \& Keith, 1897; Pick et al; Brathwaite, 1952). The most common type of variation is the anastomosis between OBA of internal iliac origin \& inferior epigastric of external iliac origin. Out of these only in $30 \%$ of cases this anastomosis opens up to become accessory obturator artery, replacing the normal branch from the internal iliac artery (Bergman et al.).

Pick et al. have documented that the OBA arising from the posterior division of the internal iliac artery can occur in $3.28 \%$ of cases in western population. Although similar (same site of origin) to the Pick et al's findings, our observation of incidence of origin of left OBA is only
$0.5 \%$ (one out of 316 pelvises). Further the exact site of origin has been documented in this study, which is at a distance of $8 \mathrm{~mm}$ distal to the point of bifurcation of the internal iliac artery. This rare abnormality in Indian population may be due different set of environmental or genetic factors. Thus influencing the development of pelvic vessels differently.

The OBA arises comparatively late in development as a supply to a plexus which in turn is joined by the axial artery of lower limb that and accompanies the sciatic nerve (Sanduno et al., 1993). It is currently accepted that the anomalies that affect the arterial patterns of the limbs are based on an unusual selection of channels from primary capillaries (Arey). The most appropriate channel enlarges whilst others retract and disappear thereby establishing the final arterial pattern (Fitzerald, 1978). In this case of persistence of vascular channels in relation to the posterior division might have resulted in giving rise to OBA, 
KUMAR, D. \& RATH, G. Anomalous origin of oburator artery from the internal iliac artery. Int. J. Morphol., 25(3):639-641, 2007.

whereas the vascular channels related to the anterior division of the internal iliac artery destined for the OBA got obliterated.

In the cases of ligation of the internal iliac arteries and their branches in women undergoing pelvic surgery, on postoperative angiography, it is seen that collateral channels start functioning soon after surgery (Chait et al., 1968). Also in cases of obstruction of the anterior division of internal iliac artery due to any cause, there will be sparing of OBA and its branches especially the branch to the head of femur. The parietal branches of OBA are important collaterals in aortoiliac and femoral arterial occlusive diseases. Therefore this may be considered for a possible bypass grafting in cases of ischemic necrosis of head of femur following decreased blood flow through OBA, connecting the posterior division to the distal end of the obstruction. Moreover, the increased length of the left OBA, owing to the origin from the posterior division of internal iliac, may have an additional advantage while grafting. Thus to avoid complications during surgery the radiologists and pelvic surgeons should be aware of this rare variation.

KUMAR, D. \& RATH, G. Origen anómalo de la arteria obturatriz de la arteria iliaca interna. Int. J. Morphol., 25(3):639-641, 2007.

RESUMEN: La arteria obturatriz es frecuentemente una rama de la división anterior de la arteria iliaca interna o uno de los ramos parietales de la arteria iliaca interna. Sin embargo, ella atrae la atención de cirujanos pélvicos, anatomistas y radiologistas por la alta frecuencia de variaciones, tanto en su origen como en su trayecto. Este reporte muestra un caso en que la arteria obturatriz se origina de la parte posterior de la arteria iliaca interna en 316 pelvis examinadas, una rara observación en la población de la India. Esta variación es correlacionada con el desarrollo y se discuten sus implicancias clínicas.

PALABRAS CLAVE: Arteria obturatriz; Variación anatómica.

\section{REFERENCES}

Arey, L. B. The development of peripheral blood vessels. In The peripheral Blood Vessels (Ed Orbison J L \& Smith D E), 1-16, Baltimore: Williams and Wilkins, 1963.

Bergman, R. A.; Thompson, S. A.; Afifi, A. K. \& Saadeh, F. A. Compendium of Human Anatomic variation: catalog, Atlas and World Literature. Urban and Schwazenberg, Baltimore and Munich, 1988.

Brathwaite, J. L. Variations in origin of the parietal branches of the Internal iliac artery. J. Anat. 86:423-30, 1952.

Chait, A.; Moltz, A. \& Nelson James H. The collateral arterial circulation in the pelvis: An angiographic study Am. J. Roentgenol., 102(2):392-400, 1968.

Fitzerald, M. J. T. Human Embryology, New York, Harper International., 1978. pp. 38-56

Parson, S. F. G. \& Keith, A. Sixth annual report of the committee of collective investigation of the Anatomical Society of Great Britain and Ireland, 1895-96. J. Anat. Physiol, 31:31-44, 1897.
Pick, J, W.; Anson, B. \& Ashley, F. L. The origin of the OBA artery. Am. J. Anat., 70:317-43, 1942.

Sanduno, J. R.; Roig, M.; Rodriguez, A.; Ferreira, B. \& Domenech, J. M. Rare origin of the OBA, inferior epigatric and femoral arteries from a common trunk. J. Anat. 183(Pt1): 161-3, 1993.

\author{
Correspondence to: \\ Dr. Dinesh Kumar \\ Department of Anatomy, \\ Maulana Azad Medical College, New Delhi \\ INDIA
}

Phone: 9101123239271

Email: dinesharyain@hotmail.com

Received: 12-03-2007

Accepted: 05-07-2007 
